\title{
B-cell anergy: from transgenic models to naturally occurring anergic $B$ cells?
}

\author{
John C. Cambier ${ }^{\star}$, Stephen B. Gauld ${ }^{*}$, Kevin T. Merrell ${ }^{*}$, and Barbara J. Vilen ${ }^{\ddagger}$ \\ "Department of Immunology, University of Colorado Health Science Center and National Jewish \\ Medical Research Center, 1400 Jackson Street, Denver, Colorado 80206, USA \\ ‡Department of Microbiology and Immunology, University of North Carolina at Chapel Hill, Chapel \\ Hill, North Carolina 27599, USA
}

\begin{abstract}
Anergy, a condition in which cells persist in the periphery but are unresponsive to antigen, is responsible for silencing many self-reactive B cells. Loss of anergy is known to contribute to the development of autoimmune diseases, including systemic lupus erythematosus and type 1 diabetes. Multiple transgenic mouse models have enabled the dissection of mechanisms that underlie anergy, and recently, anergic B cells have been identified in the periphery of wild-type mice. Heterogeneity of mechanistic concepts developed using model systems has complicated our understanding of anergy and its biological features. In this Review, we compare and contrast the salient features of anergic B cells with a view to developing unifying mechanistic hypotheses that explain their lifestyles.
\end{abstract}

The generation of B cells occurs throughout life and proceeds through several distinct stages and checkpoints (FIG. 1). After birth, B-cell generation occurs in the bone marrow, where cells progress through pro-B-cell and pre-B-cell stages of development. At the next stage (as immature $\mathrm{B}$ cells), they acquire antigen specificity by virtue of expression of a functional Bcell receptor (BCR); this is also the first key specificity checkpoint in B-cell development. Cells that successfully traverse this phase enter the periphery as transitional B cells.

The ability of the adaptive immune system to provide protection against pathogens requires a diverse BCR repertoire that can recognize a broad range of foreign proteins. Diversity is generated early in development by random rearrangement of immunoglobulin genes. This inevitably results in the genesis of receptors that recognize self antigens. It is estimated that $75 \%$ of human early immature B cells are self-reactive ${ }^{1}$. About a third of these self-reactive immature B cells are purged from the repertoire by receptor editing, wherein renewed immunoglobulin gene rearrangement generates a new light chain to pair with the existing immunoglobulin heavy chain in an anthropomorphic effort to generate a non-self-reactive

(C) 2007 Nature Publishing Group

Correspondence to J.C.C. cambierj@njc.org.

Competing interests statement

The authors declare no competing financial interests.

DATABASES

The following terms in this article are linked online to: Entrez Gene:

http://www.ncbi.nlm.nih.gov/entrez/query.fcgi?db=gene BAFF | BIM | CCR7 | CD40 | CD40L | CD86 | CXCL13 | DOK1 | ERK | FAS | FASL | LYN | PKC5 | SHIP1 | SYK

FURTHER INFORMATION

John C. Cambier's homepage: http://www.uchsc.edu/immuno/faculty/profiles/facultyrev/cambierj.htm

Access to this links box is available online. 
$\mathrm{BCR}^{2,3}$. Failing this, these B cells are deleted by apoptosis ${ }^{4}$. Despite these mechanisms of central tolerance, many self-reactive B cells escape to the periphery where they are silenced by an induced state of unresponsiveness known as anergy (BOX 1). Anergy can be viewed as nothing more than the state of lethargy that ensues when B cells mount a normal initial response to antigen but fail to receive secondary signals that sustain their activation. Paradoxically, the maintenance of anergy requires chronic binding of antigen and signal transduction, yet the stimulation of unoccupied receptors fails to trigger signal transduction pathways that are required for B-cell activation and/or differentiation.

Anergic B cells have several features that distinguish them from naive B cells. However, these features vary among models of B-cell anergy. The features include, but are not limited to, reduced lifespan, altered migration and anatomical localization, and an inability to interact productively with helper $\mathrm{T}$ cells. These mechanisms act in concert to limit the ability of anergic cells to participate in immune responses. Classically, B-cell anergy has been studied using transgenic mouse models in which antigen specificity is fixed. Many features of anergic cells observed in transgenic models are shared by a recently defined population of naturally occurring anergic B cells, known as An1 B cells. In this Review, we compare mouse models of B-cell anergy in an effort to define unifying concepts that explain how anergy is maintained. The first section introduces the models, defines the antigen specificity of each and briefly describes the attributes of the various systems. The second section focuses on the biochemical and phenotypic characteristics of B cells in each model. The salient features of each model are summarized in TABLE 1.

\section{Immunoglobulin-transgenic anergy models}

\section{The hen-egg-lyzozyme-specific model}

The most widely studied transgenic model of B-cell anergy uses hen-egg lysozyme $(\mathrm{HEL})^{5-8}$ as a neo-self antigen. To construct this model (designated MD4 $\times$ ML5), MD4 mice were engineered to co-express transgenes encoding immuno globulin heavy chains (both $\mu$ and $\delta$ heavy chains) and light chains to produce a BCR with high affinity for HEL (approximately $\left.2 \times 10^{-9} \mathrm{M}\right)^{6}$. These mice were bred with a second transgenic strain that expresses soluble HEL, referred to as ML5 mice. Although most B cells from MD4 $\times$ ML5 mice express a BCR that recognizes HEL, B-cell development proceeds relatively normally as indicated by the presence of transitional 1 (T1), T2, T3 and follicular B-cell subsets in the periphery. However, the absolute number of mature follicular B cells is substantially less than that observed in MD4 mice and a strong skewing towards the T3 B-cell stage is evident. Importantly, chronic exposure of the peripheral B cells in these mice to HEL (serum levels greater than 10-20 ng per ml) results in anergy. As a consequence, these mice fail to mount adaptive responses (as determined by serum antibody titres) following immunization with exogenous $\mathrm{HEL}^{6}$, and they exhibit a reduced capacity to generate antibody-secreting cells in response to the Toll-like receptor (TLR) agonists CpG-containing DNA and lipopolysaccharide (LPS $)^{9,10}$.

\section{The DNA-specific models}

The presence of serum antibodies specific for DNA is a defining feature in the autoimmune disease systemic lupus erythematosus (SLE), as well as in mouse models of this disease, such as MRL.Fas ${ }^{I p r / / p r}$ mice. Immunoglobulin-transgenic mice (transgenic for the $\mu$ heavy chain only) were generated to express a DNA-specific immunoglobulin-heavy-chain variable region (3H9) derived from a MRL.Fas ${ }^{l p r / p r}$ mouse with disease ${ }^{11}$; the transgenic heavy chain pairs with endogenous light chains generating mice designated $\mathrm{V}_{\mathrm{H}} 3 \mathrm{H} 9$. Therefore, $\mathrm{V}_{\mathrm{H}} 3 \mathrm{H} 9$ mice have a polyclonal B-cell repertoire enriched for $\mathrm{B}$ cells specific for single-stranded DNA (ssDNA) and double-stranded DNA (dsDNA), in addition to a 
population of non-DNA-specific B cells ${ }^{12} \cdot \mathrm{V}_{\mathrm{H}} 3 \mathrm{H} 9$ mice (on a BALB/c background) produce normal numbers of $\operatorname{IgM}^{+} \mathrm{B}$ cells in the periphery yet do not contain DNA-specific serum antibodies, indicating that the DNA-specific B cells in these mice are anergic ${ }^{12}$. Similarly, when the $\mathrm{V}_{\mathrm{H}} 3 \mathrm{H} 9$ heavy chain is forced to pair with the ssDNA-specific light chain $(\mathrm{V} \kappa 8)$ in double-transgenic mice $\left(\mathrm{V}_{\mathrm{H}} 3 \mathrm{H} 9 \times \mathrm{V} \kappa 8\right.$ mice), normal numbers of $\operatorname{IgM}^{+} \mathrm{B}$ cells are found in the periphery ${ }^{13}$ but no ssDNA-specific antibodies are detected in the serum ${ }^{14}$. The anergic phenotype of $\mathrm{B}$ cells from the $\mathrm{V}_{\mathrm{H}} 3 \mathrm{H} 9$ mice is breached when these mice are crossed with the autoimmune-prone MRL.Fas ${ }^{\text {pr/lpr }}$ mice, as demonstrated by the presence of DNA-specific antibodies in the serum of 10-week-old $\mathrm{V}_{\mathrm{H}} 3 \mathrm{H} 9 \times$ MRL.Faslpr/pr mice ${ }^{15}$. It should be noted that the levels of serum DNA-specific antibody in these mice mirror those of non-transgenic MRL. Fas ${ }^{l p r / p r}$ mice $^{15}$. In a third DNA-specific model of anergy, pairing of the $\mathrm{V}_{\mathrm{H}} 3 \mathrm{H} 9$ heavy chain with a transgenic $\mathrm{V}_{\lambda} 2$ light chain produces dsDNA-specific B cells. In these $\mathrm{V}_{\mathrm{H}} 3 \mathrm{H} 9 \times \mathrm{V}_{\lambda} 2$ mice, $\operatorname{IgM}^{+} \mathrm{B}$ cells are present in the periphery (albeit in reduced numbers) but no serum dsDNA-specific antibodies are detectable, again consistent with the efficient induction of anergy of the autoreactive B cells ${ }^{13}$.

\section{The Smith-antigen-specific model}

Smith antigen (Sm)-specific B cells are dysregulated in 25-30\% of patients with SLE ${ }^{16}$. Sm, a component of the small nuclear ribonucleoprotein (snRNP) complex involved in premRNA splicing, can activate B cells through the BCR and TLR7 (REF. 17). To define how tolerance to this proteinaceous nuclear self antigen is maintained, Sm-specific immunoglobulin-transgenic mice (with a $\mu$ heavy chain only) were developed. These mice express a heavy chain $\left(\mathrm{V}_{\mathrm{H}} 2-12\right)$ identified in B cells from MRL.Fas ${ }^{\text {pr/lpr }}$ mice with disease $^{18}$. The $\mathrm{V}_{\mathrm{H}} 2-12$ pairs with endogenous light chains to produce a B-cell repertoire in which most cells are Sm specific, but vary in affinity ${ }^{19,20}$. Transitional (T1 and T2) and follicular B-cell subsets are found at normal frequencies, however $\mathrm{V}_{\mathrm{H}} 2-12$ mice exhibit a twofold increase in marginal-zone $\mathrm{B}$ cells and early pre-plasma cells ${ }^{19-21}$. Although $\mathrm{V}_{\mathrm{H}^{2}}{ }^{2}$ 12 mice do not spontaneously secrete Sm-specific antibody, immunization with snRNPs induces a Sm-specific response, indicating that a subset of B cells fails to be tolerized or that immunization overcomes tolerance ${ }^{22}$. Similar to the DNA-specific model, $\mathrm{V}_{\mathrm{H}} 2-12$ mice crossed with autoimmune-prone MRL.Fas ${ }^{l p r / / p r}$ or B6.Fas ${ }^{l p r / p r}$ mice spontaneously produce Sm-specific antibody by 8 weeks of age ${ }^{19,21}$. This shows that although effectively silenced on a non-autoimmune background, tolerance is lost on an autoimmune-prone background.

To study how low-affinity Sm-reactive B cells are tolerized, a model was generated wherein the light chain of $\mathrm{V}_{\mathrm{H}} 2-12$ mice was restricted to $\mathrm{V}_{\mathrm{K}} 8$. This heavy-light chain pairing was identified in MRL.Fas ${ }^{l p r / p r}$ mice and proposed to bind Sm with low affinity ${ }^{23,24}$. The $\mathrm{V}_{\mathrm{H}^{2}}{ }^{2}$ $12 \times \mathrm{V} \times 8$ mice have normal frequencies of follicular, T1 and T2 B cells but are deficient in marginal-zone $\mathrm{B}$ cells ${ }^{24}$. The $\mathrm{B}$ cells from $\mathrm{V}_{\mathrm{H}} 2-12 \times \mathrm{V}_{\mathrm{K}} 8$ mice neither spontaneously secrete immunoglobulin ${ }^{24}$ nor produce $\mathrm{Sm}$-specific antibody on immunization with snRNPs (M.A. Kilmon and B.J.V., unpublished observations). This suggests that the low affinity ( $\mathrm{V}_{\mathrm{K}}$ 8-expressing) $\mathrm{B}$ cells in $\mathrm{V}_{\mathrm{H}} 2-12 \times \mathrm{V}_{\mathrm{K}} 8$ mice are not responsible for the loss of tolerance seen when the concentration of snRNPs is increased. Furthermore, these data suggest that unique mechanisms may be responsible for anergic silencing of B cells that express BCRs of different affinities for antigen. Alternatively, the binding avidity of snRNPs may simply be too low to activate B cells bearing these low affinity receptors.

\section{The insulin-specific model}

Another model of B-cell anergy was developed to study tolerance to insulin. In this model, transgenes encoding the $\mu$ heavy- and light-chain V-region genes from the insulin-specific $125 \mathrm{~B}$-cell hybridoma (generated during a primary immune response in $\mathrm{BALB} / \mathrm{c}$ mice to 
human insulin, with an affinity of $1 \times 10^{-7} \mathrm{M}$ for rodent insulin ${ }^{25}$ ) were introduced into C57BL/6 mice ${ }^{26}$; these mice were crossed with diabetes-prone NOD (non-obese diabetic) mice. On both C57BL/6 and NOD backgrounds, $\mathrm{B}$ cells from $\mathrm{V}_{\mathrm{h}} 125 \times \mathrm{V}_{\mathrm{K}} 125$ mice (also known as $125 \mathrm{Tg}$ mice) develop normally to become follicular and marginal-zone B cells ${ }^{27}$. However, these mice fail to spontaneously secrete insulin-specific antibodies and fail to generate insulin-specific antibodies on immunization with bovine or porcine insulin ${ }^{26}$. Despite the apparent anergic phenotype of the insulin-specific B cells, $\mathrm{V}_{\mathrm{H}} 125 \times$ $\mathrm{V}_{\kappa} 125$.NOD mice develop diabetes at a similar rate to non-transgenic NOD mice ${ }^{27}$. This suggests that in this system chronic exposure to insulin causes a less stringent form of anergy. The reason for this is unclear, but it may be due to the affinity of the transgenic BCR for insulin, the availability of sufficient insulin or the avidity of available insulin.

\section{The arsonate-specific model}

B cells from the azophenyl-arsonate (Ars)-specific model (also known as the Ars/A1 model) express surface immunoglobulin $(\operatorname{IgM}$ and $\operatorname{IgD})$ that has moderate affinity $\left(2.5 \times 10^{-5} \mathrm{M}\right)$ for the Ars hapten ${ }^{28}$. In this model, Ars-specific B cells progress through T1, T2 and T3 Bcell stages, however, follicular and marginal-zone B cells are poorly represented ${ }^{29}$. The peripheral populations are greatly enriched in T3 cells. Importantly, the Ars-specific BCR crossreacts with 100 times lower affinity to ssDNA, resulting in anergy, as indicated by the unresponsiveness of these mice to Ars-containing immunogens. The Ars-specific system, by virtue of receptor crossreactivity with self, provides an excellent model of pathogen mimicry of self antigen. In addition, high-affinity hapten reactivity has been invaluable in allowing analysis of the reversibility of anergy. Competition studies showed that the anergic state of Ars-specific B cells can be reversed in vitro by culture in the presence of a monovalent hapten (Ars-tyrosine) of higher affinity than the self antigen for the $\mathrm{BCR}^{30}$. Upon recovery from the anergic state (which occurs within seconds), some defects in signal transduction are lost and cells become responsive to Ars-containing immunogens. These results indicate that anergy is not maintained by a mechanism such as genetic reprogramming. The ability to reverse anergy was also demonstrated using the MD4 $\times$ ML5 system. In this model, anergic B cells remained unresponsive for $\sim 48$ hours following transfer of the cells to an antigenfree animal ${ }^{5}$. This delay may reflect the inability to displace high-affinity antigen from the BCR.

\section{Naturally occurring anergic B cells}

Although the use of BCR-transgenic models has contributed seminally to our understanding of B-cell anergy, the issue of whether such models accurately reflect naturally occurring tolerance mechanisms has always been a concern. Perhaps more fundamental was the question of the physiological importance of anergy in silencing self-reactive B cells. These issues were largely addressed by the recent identification of naturally occurring anergic $\mathrm{B}$ cells in the periphery of non-autoimmune C57BL/6 mice ${ }^{29}$. By comparing the expression of a range of cell-surface markers on anergic B cells from different BCR-transgenic models, it was shown that both the Ars- and the HEL-specific mouse models are characterized by the development of a subset of B cells with a cell-surface phenotype that corresponds to that previously reported for T3 B cells (FIG. 1). T3 B cells from C57BL/6 mice were found to be enriched in self-reactive cells (compared with other B-cell subsets) and exhibited other markers of anergy, including attenuated BCR-mediated signalling. Importantly, BCRtransgenic mice expressing only non-autoreactive B cells, such as MD4 mice, do not contain T3 B cells. Finally, mature MD4 B cells rapidly adopt the T3 B-cell phenotype upon transfer to ML5 mice. It is therefore apparent that the T3 B-cell stage is perhaps not strictly transitional, and these cells have been designated An1 B cells. Although the An1 B-cell population is predominant in Ars- and HEL-specific models, it is negligible in the Sm- or insulin-specific models, suggesting that An1 B cells may reflect only one of multiple anergic 
phenotypes found in the periphery. Nevertheless, the existence of An1 B cells in a physiological repertoire demonstrates that anergy is biologically important. Finally, these studies confirm the fidelity of transgenic mice as models of physiological B-cell anergy. Importantly, the short lifespan of physiological An1 B cells $(\sim 5 \text { days })^{83}$, relative to most peripheral B cells ( $\sim 40$ days), considered in the context of An1 B-cell frequency ( 6-8\%), suggests that in normal animals $\sim 50 \%$ of newly formed B cells are destined to become anergic. Finally, recent work has shown that the T3 B-cell population is reduced in lupusprone mouse models addressing a possible pathogenic role for these self-reactive $\mathrm{B}$ cells in autoimmunity ${ }^{31}$.

\section{Characteristics of anergic B cells}

In the following section, we review the phenotypic characteristics of anergic B cells from the extant models. In particular, we highlight the heterogeneity among models and suggest potential underlying bases for these variations.

\section{Developmental 'arrest'}

The differentiation of mature B cells into plasma cells (FIG. 1) is required for the high level of secretion of antibody seen in an immune response. Logically, preventing self-reactive B cells from differentiating should limit the generation of pathogenic autoantibodies.

Accordingly, reports have identified several stages of B-cell development at which B cells expressing a self-reactive BCR are arrested. As mentioned, in MD4 $\times$ ML5 and Ars-specific mice, a significant proportion of peripheral B cells would appear (see earlier) to be arrested at the T3 B-cell stage, exhibiting a surface phenotype identical to that of An1 B cells in wild-type mice. Similarly, dsDNA-specific $B$ cells from $\mathrm{V}_{\mathrm{H}} 3 \mathrm{H} 9$ and $\mathrm{V}_{\mathrm{H}} 3 \mathrm{H} 9 \times \mathrm{V}_{\lambda} 2$ mice show such a developmental defect. These $B$ cells arrest at an immature and/or transitional stage, again limiting the number of cells entering the mature B-cell population ${ }^{13,32}$. The importance of this checkpoint for maintaining tolerance is clearly highlighted by the breach in this developmental block that occurs in autoimmune-prone MRL.Fas ${ }^{l p r} /$ lpr $\mathrm{V}_{\mathrm{H}} 3 \mathrm{H} 9 / \mathrm{V}_{\lambda} 2$ mice, in which B-cell progression to full maturity parallels disease development ${ }^{15}$. Smspecific splenic $B$ cells from $\mathrm{V}_{\mathrm{H}} 2-12$ mice arrest at a later stage in development, as early pre-plasma cells $\left(\mathrm{CD} 19^{+} \mathrm{CD} 138^{\mathrm{mid}}\right)^{21}$. Interestingly, ssDNA- and Sm-specific splenic B cells (from $\mathrm{V}_{\mathrm{H}} 3 \mathrm{H} 9 \times \mathrm{V}_{\mathrm{K}} 8$ mice and $\mathrm{V}_{\mathrm{H}^{2}}-12 \times \mathrm{V}_{\mathrm{K}} 8$ mice, respectively) do not exhibit a block in development and have mature follicular $\mathrm{B}$ cells that populate the spleen ${ }^{33}$.

It is unclear why autoreactive B cells arrest at different stages of development. It seems likely that the B cells with low affinity and/or avidity for self antigen, such as in $\mathrm{V}_{\mathrm{H}} 125 \times$ $\mathrm{V}_{\mathrm{K}} 125, \mathrm{~V}_{\mathrm{H}} 3 \mathrm{H} 9 \times \mathrm{V}_{\mathrm{K}} 8$ and $\mathrm{V}_{\mathrm{H}} 2-12$ mice, may be deemed to be of less risk to the host and allowed to proceed through development. Regardless, given the variation among anergy models in B-cell development, it is clear that mechanisms other than developmental regulation must ensure that these cells don't run riot.

\section{Decreased lifespan}

It is widely accepted that anergic B cells have a half-life that is considerably shorter than non-self-reactive mature B cells in vivo (1-5 days as opposed to 40 days ${ }^{34,35}$ ). A reduced lifespan is thought to purge the repertoire of potentially harmful B cells. However, in early studies using MD4 $\times$ ML5 animals, the survival of anergic HEL-specific B cells was shown to be indistinguishable in vivo from that of non-self-reactive B cells, suggesting that anergic $B$ cells have no intrinsic survival defects ${ }^{36}$. Subsequently it was shown that, when competing with non-anergic B cells, the half-life of anergic B cells is substantially decreased $^{36,37}$. It was years before the underlying basis of this phenomenon was defined. The discovery of B-cell-activating factor (BAFF; also known as BLYS) as a major survival 
factor for peripheral B cells was key to resolving this issue ${ }^{38}$. It was shown that anergic B cells compete poorly with non-anergic B cells for limited ambient BAFF ${ }^{39}$. The signal provided by BAFF is thought to be required to override the high levels of pro-apoptotic proteins, such as BIM (BCL-2-interacting mediator of cell death), that are present in anergic cells owing to chronic self-antigen-induced signalling through the BCR. Indeed, the deletion of Bim in MD4 $\times$ ML5 mice has been shown to result in the production of HEL-specific antibodies ${ }^{40}$.

The shortened half-life of anergic B cells has also been recognized in other models. Bromodeoxyuridine (BrdU)-incorporation experiments have confirmed increased turnover rates in ssDNA- and dsDNA-specific models ${ }^{14,24,41}$, but not for anergic B cells from the insulin- or Sm-specific models.

Although competition for BAFF is probably important, it is unlikely to be the sole cause of the short half-life of anergic B cells. We have shown that the removal of self antigen in vitro by competition with monovalent hapten can result in a substantial recovery of the half-life of anergic cells, suggesting that chronic BCR signalling is required to initiate pro-apoptotic pathways ${ }^{30}$. Alternatively, self-antigen-induced signalling may alter the BAFF response through 'receptor crosstalk'.

Another mechanism for the deletion of self-reactive B cells is FAS-mediated apoptosis consequent to interaction with FAS ligand (FASL)-expressing $\mathrm{CD}^{+} \mathrm{T}$ cells. Several lines of evidence suggest that this may be an important mechanism. First, mice deficient in either FAS (MRL.Fas ${ }^{l p r / p r}$ ) or FASL (B6.Fas ${ }^{l g l d g l d}$ ) are prone to spontaneous autoimmunity with age (reviewed in REF. 42). Second, the interaction of anergic HEL-specific B cells with HEL-specific $\mathrm{CD}^{+} \mathrm{T}$ cells results in B-cell apoptosis and not a break in B-cell anergy ${ }^{43}$. Last, overexpression of the co-stimulatory molecule CD86 has been shown to prevent FASmediated deletion of $\mathrm{B}$ cells by HEL-specific $\mathrm{CD} 4^{+} \mathrm{T}$ cells and results in the production of HEL-specific antibodies, indicating a break in anergy ${ }^{44}$. Notably, not all anergic B cells express FAS, suggesting that FAS-mediated deletion in anergy is not a universal mechanism of tolerance.

Paradoxically, in vivo studies also suggest that $\mathrm{T}$ cells (adoptively transferred allogeneic $\mathrm{T}$ cells) are capable of breaking B-cell anergy in the HEL-specific model in which HEL is present in its soluble form ${ }^{45}$. This is complemented by data showing that both cognate and allogeneic T cells break anergy in DNA-specific models in vivo ${ }^{46,47}$. However, another study reported an inability of allogeneic T cells to break anergy in the HEL-specific system, unless HEL was provided as a membrane-bound form ${ }^{48}$. The ability of the membrane-bound form of HEL to break B-cell anergy in the presence of allogeneic $\mathrm{T}$ cells might be related to its higher avidity for the HEL-specific BCR and hence its ability to deliver a qualitatively stronger signal to anergic B cells. Interestingly, anergic HEL-specific B cells exposed to forms of HEL that efficiently crosslink the BCR have been shown to be resistant to FASmediated apoptosis ${ }^{49}$. Together, these data set precedence for T-cell-mediated reversal of Bcell anergy, and suggest that the level of BCR crosslinking by self antigen can determine both the outcome of this response and the sensitivity to FAS-mediated apoptosis. One point to be kept in mind when interpreting studies on the role of T-cell help in reversing B-cell anergy is the availability of T-cell help relative to the timing of self-antigen-induced signalling. Cook et al. ${ }^{50}$ have shown that T-cell-derived signalling must be available soon after self-antigen-induced signals are delivered to the B cells to prevent the induction of anergy. 


\section{Altered localization}

The localization of B cells in appropriate microenvironments of secondary lymphoid organs is essential for the development of B-cell immunity. Specifically, localization to follicular regions of the spleen is thought to allow effective sampling of protein antigens in an environment that is rich in B-cell survival factors.

Early studies using MD4 $\times$ ML5 mice, in which a monoclonal HEL-specific anergic population exists, suggested that the anergic B cells traffic normally within secondary lymphoid organs ${ }^{36}$. However, when anergic B cells coexist with non-anergic B cells (after adoptive transfer into wild-type mice), their trafficking characteristics were altered. In studies by Cyster et al. ${ }^{36}$, it was shown that under conditions of competition anergic B cells failed to enter the B-cell follicular areas, instead arresting at the T-cell-B-cell boundary in a process known as follicular exclusion. Recently, Reif et al. ${ }^{51}$ characterized a mechanism for the trafficking of B cells within the spleen and lymph nodes. Naive B cells are attracted to the follicular area by chemotaxis to CXC-chemokine ligand 13 (CXCL13). Following antigen encounter, these cells upregulate the expression of CC-chemokine receptor 7 (CCR7), which increases their sensitivity to the chemo-kines CCL19 and CCL21 that are present in the T-cell zone. This promotes B-cell migration to the T-cell areas, allowing productive T-cell-B-cell collaboration. Perhaps not surprisingly, anergic B cells act as though they have received BCR signals and accumulate in cortical areas where they search for help from $\mathrm{T}$ cells.

Follicular exclusion has been observed in other anergy models, including $\mathrm{V}_{\mathrm{H}} 3 \mathrm{H} 9$ mice ${ }^{32}$ and in dsDNA-specific B cells from $R g^{-1-} \mathrm{V}_{\mathrm{H}} 3 \mathrm{H} 9 / \mathrm{V}_{\lambda} 2$ mice transferred into wild-type hosts $^{33}$. This is in contrast to ssDNA-specific B cells (from $\mathrm{V}_{\mathrm{H}} 3 \mathrm{H} 9 \times \mathrm{V}_{\kappa} 8$ mice) ${ }^{33}$ and $\mathrm{B}$ cells from Sm-specific $\left(\mathrm{V}_{\mathrm{H}} 2-12\right)$ models ${ }^{24}$, which all enter B-cell follicles effectively. It is currently unclear where An1 B cells reside in secondary lymphoid tissue, although it would be interesting to determine their localization.

\section{Effects of innate immune signals}

TLRs and their agonists have key roles in innate and adaptive immunity and contribute to autoimmunity ${ }^{17,52}$. Two mechanisms are known to modulate the function of self-reactive $B$ cells during innate immune responses. The first was defined in the MD4 $\times$ ML5 model, in which chronic antigen stimulation reduces plasma-cell generation and antibody secretion following stimulation of TLR9 (with CpG-containing DNA) and TLR4 (with LPS) in vitro. The repression of the TLR-mediated antibody secretion response is dependent on MEKs (mitogen-activated protein kinase (MAPK)/extracellular-signal-regulated kinase (ERK) kinases $)^{9,10}$. A second mechanism was defined in the Sm-specific model, in which dendritic cells (DCs) and macrophages selectively repress antibody production by self-reactive B cells but not naive $\mathrm{B}$ cells ${ }^{53}$. Repression is partly mediated by soluble factors, such as interleukin-6 (IL-6) and soluble CD40 ligand (CD40L), secreted by activated DCs and macrophages, and by an ill-defined, contact-dependent mechanism ${ }^{53-55}$. So, chronic binding of self antigen may reprogram IL-6 receptor and CD40 signalling, leading to alternative outcomes in autoreactive B cells. These findings raise the possibility that whereas BCR signals triggered by high-avidity self antigen are sufficient to silence autoreactive B cells, BCR signals triggered by low-avidity self antigen may require complementation by additional or unique mechanisms.

During innate immune responses, naive B cells proliferate and upregulate their expression of co-stimulatory molecules in response to TLR ligation. By contrast, some autoreactive B cells proliferate, yet maintain anergy and fail to secrete immunoglobulin in response to TLR ligation ${ }^{5,13,14,27,41,55}$ (S.B.G. and J.C.C., unpublished observations). This suggests no 
obligate link between antibody secretion and proliferation. There is a similar relationship between the upregulation of expression of co-stimulatory molecules and antibody secretion. LPS upregulates CD86 expression on anergic B cells from HEL-specific ${ }^{56}$, Ars-specific ${ }^{30}$ and insulin-specific $\left(\mathrm{V}_{\mathrm{H}} 125 \times \mathrm{V}_{\mathrm{K}} 125\right)^{27}$ models, despite a lack of antibody secretion. Interestingly, B cells from the insulin-specific model fail to proliferate in response to LPS, yet they upregulate CD86 expression ${ }^{27}$. This suggests that although some TLR4 signaltransduction pathways remain intact in anergic B cells, others do not.

\section{BCR signalling in B-cell anergy}

Antigen-induced aggregation of the BCR on normal mature B cells results in the initiation of signalling cascades that culminate in proliferation, the upregulation of co-stimulatory molecules and alterations in gene transcription. By contrast, many anergic B cells are defective in these responses. Downmodulation of surface IgM on anergic cells was thought to be partly responsible for diminished downstream signalling responses. However, this seems unlikely for three reasons. First, HEL- and Ars-specific anergic B cells express normal, if not higher, levels of surface $\operatorname{IgD}^{6,28}$, resulting in the same overall antigen-binding capacity between the anergic B cells and naive B cells. Yet antibody-mediated aggregation of total surface immunoglobulin in both systems does not induce productive downstream signalling. Second, Ars-specific B cells have only a modest reduction $(\sim 30 \%)$ in surface IgM. Third, only a fraction (10\%) of the total surface IgM on naive B cells must be aggregated to induce most responses ${ }^{57,58}$.

Elucidation of the signalling defects in anergic cells will undoubtedly shed light on the mechanism(s) by which chronic antigen exposure attenuates signalling by unoccupied BCRs. Interestingly, defects have been noted in the most receptor-proximal signalling events following acute antigen stimulation of anergic cells. In anergic B cells from MD4 × ML5 mice, BCR aggregation fails to induce tyrosine phosphorylation of Iga and $\operatorname{Ig} \beta$ or SYK (spleen tyrosine kinase), despite expression of these proteins at levels comparable to nonanergic B cells ${ }^{48,59}$. Similar observations have been made in Ars-specific B cells (K.T.M., J. M. Dal Porto, S.B.G. and J.C.C., unpublished observations) and dsDNA-specific B cells (from $\mathrm{V}_{\mathrm{H}} 3 \mathrm{H} 9 \times \mathrm{V}_{\lambda} 2$ mice) ${ }^{33}$, although the provision of T-cell-derived signals to these dsDNA-specific B cells in vitro results in the recovery of defective BCR-mediated SYK phosphorylation. BCR 'desensitization' or defective signalling in B cells chronically exposed to self antigen may occur by ineffective aggregation of surface immunoglobulin, ineffective association between surface immunoglobulin and its signalling components Iga and $\operatorname{Ig} \beta$, or repression of BCR signal transduction by phosphatases (see later).

More distal effects of BCR-mediated signalling are also affected in anergic cells. For example, HEL-specific B cells from MD4 $\times$ ML5 mice fail to mobilize intracellular $\mathrm{Ca}^{2+}$ following BCR aggregation, although these cells have a constitutive increase in basal intracellular $\mathrm{Ca}^{2+}$ levels $(\sim 50 \mathrm{nM})$ compared with follicular cells ${ }^{48,59,60}$. Similarly, despite the increased basal levels of phosphorylated LYN and ERK in HEL-specific B cells, the phosphorylation of these key signalling molecules is not further increased on stimulation of the BCR with HEL or IgM-specific antibody ${ }^{60}$. Ars-specific and An1 B cells show a similar pattern of elevated basal levels of intracellular $\mathrm{Ca}^{2+}$ and phosphorylation of signalling effectors, and these effectors are also not upregulated upon stimulation with IgM-specific antibody $^{28,29}$ (S.B.G., K.T.M. and J.C.C., unpublished observations).

In some anergic models, B cells respond to BCR aggregation under certain 'extreme' circumstances, suggesting that BCR desensitization is not complete. For example, highavidity polyclonal IgM-specific antibodies induce robust tyrosine phosphorylation and intracellular $\mathrm{Ca}^{2+}$ mobilization in insulin-specific $\mathrm{B}$ cells (from $\mathrm{V}_{\mathrm{H}} 125 \times \mathrm{V}_{\mathrm{K}} 125$ mice). This 
is somewhat paradoxical because in this model, immunization with antigen fails to elicit antibody production ${ }^{61}$. This may simply reflect the ability of high-avidity crosslinkers (such as polyclonal IgM-specific antibody) to overcome tolerance induced by the low-avidity antigen-BCR inter action. This concept may be relevant to the development of SLE, as membranes of apoptotic cells contain high levels of nuclear self antigen ${ }^{20,62}$, which may be capable of overcoming tolerance induced by a lower-avidity version of the same self antigen. Alternatively, such high-avidity antigens may overcome ignorance in certain autoimmune-prone genetic backgrounds. Similarly, co-stimulation of BCRs and TLRs by apoptotic cells may preclude unresponsiveness ${ }^{63}$. Thus, multiple mechanisms may determine the responsiveness of self-reactive $B$ cells during adaptive and innate immune responses, with variables such as receptor affinity, antigen avidity and antigen availability all contributing to the overall anergic phenotype.

\section{Biological consequences of BCR signalling in anergic cells}

An important aspect of the specific defects in BCR signalling described above is whether they preclude participation of anergic $\mathrm{B}$ cells in immune responses or are epiphenomena. In normal B cells, BCR aggregation leads to the upregulation of the expression of CD80 and CD86. This enables B cells to promote T-cell activation, with subsequent B-cell proliferation and differentiation. However, anergic B cells from MD4 × ML5 and Arsspecific models fail to upregulate CD86 expression to levels similar to those for non-anergic $\mathrm{B}$ cells ${ }^{28,30,44,56}$. In addition, CD80 (which is expressed at higher than normal levels on Arsspecific B cells in the basal state but is not sufficient to drive T-cell activation) is poorly upregulated by both Ars-specific and HEL-specific B cells following BCR aggregation $28,30,44,56,64$. By contrast, BCR-mediated upregulation of CD86 expression is fully functional in insulin-specific $B$ cells from $V_{h} 125 \times V_{\kappa} 125$ mice ${ }^{27}$, yet these cells are unable to mount T-cell-dependent immune responses ${ }^{26}$. Interestingly, all of these anergic $\mathrm{B}$ cells, including those from HEL-, Ars-, ssDNA-, insulin- and dsDNA-specific models, can be stimulated by IL-4 and CD40-specific antibody in vitro, suggesting that they are capable of responding to T-cell-derived signals if they are provided in the correct context ${ }^{27,33,41,65}$ (S.B.G. and J.C.C., unpublished observations).

The physiological relevance of attenuated CD86 expression after BCR aggregation was made clear in work by Rathmell et al. ${ }^{43,44,66}$. Defective upregulation of CD86 expression promotes FAS-mediated apoptosis of HEL-specific anergic B cells by $\mathrm{CD}^{+} \mathrm{T}$ cells. Moreover, enforced expression of CD86 in these B cells was sufficient to drive proliferation and antibody production in the presence of antigen-specific $\mathrm{CD} 4^{+} \mathrm{T}$ cells. It is therefore clear that the dysregulation of attenuated CD86 expression by anergic B cells could have marked consequences for autoimmunity.

In addition to the expression of activation markers, BCR-mediated proliferation is attenuated in anergic B cells from HEL-specific (MD4 $\times$ ML5) ${ }^{5,48}$, Ars-specific (S.B.G. and J.C.C., unpublished observations), dsDNA-specific $\left(\mathrm{V}_{\mathrm{H}} 3 \mathrm{H} 9 \times \mathrm{V}_{\lambda} 2\right)^{33}$, ssDNA-specific $\left(\mathrm{V}_{\mathrm{H}} 3 \mathrm{H} 9 \times\right.$ $\left.\mathrm{V}_{\mathrm{\kappa}} 8\right)^{14,33}$ and insulin-specific $\left(\mathrm{V}_{\mathrm{H}} 125 \times \mathrm{V}_{\mathrm{\kappa}} 125\right)^{27}$ models. Whether these models share a common mechanism for this pheno type is unclear, but it is unlikely. In the MD4 × ML5 model, for example, BCR aggregation fails to induce the phosphorylation and subsequent degradation of IkB (inhibitor of nuclear factor $-\mathrm{kB}(\mathrm{NF}-\mathrm{\kappa B})$ ), which therefore prevents the nuclear translocation of NF- $\mathrm{\kappa B}$ that is necessary for gene activation and B-cell proliferation. By contrast, no such defect in I $\kappa$ B degradation is observed in Ars-specific anergic B cells (S.B.G. and J.C.C., unpublished observations).

In summary, it is clear that chronic exposure of self-reactive B cells to antigen stimulates intracellular signalling mechanisms that prevent subsequent activation of these cells to further antigen exposure. However, as is clear for other features of anergic cells, such as 
reduced lifespan, these defects are heterogeneous. This heterogeneity is perhaps best identified in the HEL- and Ars-specific models of anergy, in which similar defects in proximal BCR signalling are observed (such as defective phosphorylation of Iga, Ig $\beta$ and SYK) but distal events are differentially affected (such as IkB degradation).

\section{Mechanisms of signalling defects in anergy}

\section{Chronic versus acute signalling}

Tenets of specificity dictate that silencing of self-reactive B cells by anergy must be initiated by the binding of self antigen. B cells cannot distinguish between self and non-self antigens, therefore the decision to become anergic must be based on whether secondary signals are received within a specific time frame. It is not surprising, therefore, that an anergic state can be induced simply by treating isolated B cells with either antigen or immunoglobulinspecific antibodies for a prolonged period of time. The consequence of this receptor desensitization is a constitutive increase in the levels of intracellular free $\mathrm{Ca}^{2+}$ and tyrosine phosphorylation similar to that seen in anergic B cells from the MD4 $\times$ ML5 and Arsspecific models ${ }^{57,58}$. Two observations confirm the requirement of prolonged or constant signalling for anergy or BCR desensitization. First, anergic HEL-specific B cells that are transferred into recipients devoid of HEL regain the ability to mature (progressing past the T3 B-cell developmental stage ${ }^{29}$ ) and to mount an antibody response ${ }^{5}$. Second, many biochemical features of anergic B cells are reversed following withdrawal of the self-antigen signal $^{30,53}$. Both these lines of evidence suggest that chronic signalling in the absence of secondary signals (by $\mathrm{T}$ cells, for example) is central to the maintenance of anergy.

\section{Biased activation of inhibitory signalling circuitry in anergic cells}

As described above, chronic exposure to self antigen increases basal levels of phosphorylation of proteins such as LYN. But how does this translate into attenuated BCRmediated signalling upon restimulation? It is possible that LYN mediates an effect by phosphorylating the inhibitory co-receptor CD22 and by recruiting the phosphatase SHP1 (SH2-domain-containing protein tyrosine phosphatase 1) to the BCR complex ${ }^{67}$. However, this has not been demonstrated in most anergy models. This notwithstanding, $\mathrm{Cd} 22^{-/-}$ animals are known to produce autoantibodies spontaneously ${ }^{68}$. In addition, mice lacking LYN or expressing constitutively active LYN develop autoimmunity ${ }^{69}$, confirming a key role for LYN in B-cell anergy.

LYN has also been shown to be important in the phosphorylation and activation of the phosphatase SHIP1 (SH2-domain-containing inositol polyphosphate $5^{\prime}$ phosphatase 1) and its adaptor DOK (docking protein). These molecules form a bidentate inhibitory complex following co-aggregation of the BCR with the inhibitory Fc receptor for IgG, Fc $\gamma$ RIIb. We have recently shown that SHIP1 and DOK1 are also hyperphosphorylated in anergic B cells from the HEL- and Ars-specific models and in An1 B cells from normal mice ${ }^{29}$ (K.T.M. and J.C.C., unpublished observations). Thus, chronic BCR signalling also activates this circuit. In addition, when crossed onto a SHIP1-deficient background, anergy is lost in both the Arsand HEL-specific models, as well as in wild-type animals. Studies in our laboratory indicate that activation of SHIP1 and DOK1 in anergic cells results from biased monophosphory lation of tyrosine residues in the ITAMs (immunoreceptor tyrosine-based activation motifs) of Iga and Ig $\beta$ (FIG. 2). Dual ITAM tyrosine phosphorylation occurs in the initial B-cell response to antigen, and is required for the recruitment of SYK and for the induction of productive downstream signalling. In anergic cells, however, ITAMs are constitutively monophosphorylated. Studies of signalling by chimeric receptors in a mouse B-cell line have confirmed that monophosphorylation of the Iga and $\operatorname{Ig} \beta$ ITAMs leads to activation of the SHIP1-DOK pathway ${ }^{70}$ (K.T.M. and J.C.C., unpublished observations). 
Another signalling molecule that is thought to have a role in the induction of anergy is protein kinase $\mathrm{C} \delta$ (PKC $\delta$ ). The absence of this protein has previously been shown to result in the loss of anergy and the development of autoimmunity ${ }^{71,72}$. This may be linked to the proposed role for nuclear translocation of PKC $\delta$ in the induction of B-cell apoptosis ${ }^{73}$. Interestingly, it has been shown that BAFF prevents this translocation and hence prevents Bcell death. Given the autoimmune phenotype of mice that overexpress $\mathrm{BAFF}^{74}$ and the lack of B-cell anergy in PKC $\delta$-deficient animals, a key role for BAFF in regulating the survival of anergic B cells is likely.

It is worth noting that the use of knockout mice to determine the importance of various proteins in tolerance induction can be subject to misinterpretation. As previously mentioned, it is reported that T-cell signals only break or prevent tolerance in B cells that are recently exposed to self antigen. By extension, it is reasonable to suggest that such genetic manipulations may have effects that occur before the induction of anergy, rather than breaking anergy per se. A further confounding effect in such circumstances is the production of antibodies that neutralize the self antigen, contributing to the illusion that anergy is broken. The generation of anergic mouse models crossed with conditional knockout mice, in which the deletion of a specific gene can be induced in a specific cell population (one that is already anergic, for example), should help to resolve this problem.

\section{Trans-effects of chronic BCR signalling}

The ability of signalling molecules to act in trans between different receptors is well known. In the case of B-cell anergy, inhibitory signals generated by chronic BCR stimulation act in trans on chemokine receptors. Work by Brauweiler et al. ${ }^{75}$ has shown that migration in response to CXCL12 is inhibited in anergic B cells from Ars- and HEL-specific models and in in vitro antigen-stimulated B cells. Interestingly, this is known to be a SHIP1-dependent mechanism, which suggests that activated SHIP1 induced by prolonged exposure to self antigen might act in trans to inhibit signalling by other receptors that have a functional requirement for phosphatidylinositol-3,4,5-trisphosphate $\left(\operatorname{Ptd} \operatorname{Ins}(3,4,5) \mathrm{P}_{3}\right)$ for function. It will be interesting to examine whether other receptors expressed on $\mathrm{B}$ cells, which are known to use PtdIns $(3,4,5) \mathrm{P}_{3}$, are similarly affected. One possible candidate is the receptor for BAFF, which is known to signal through phosphoinositide 3-kinase, as anergic B cells might have a decreased capacity to respond to $\mathrm{BAFF}^{39,76}$.

\section{Concluding remarks}

It is clear that B-cell anergy is a key physiological mechanism for silencing self-reactive B cells and thereby preventing autoimmunity. However, it is also clear that anergy is complex, plastic and mechanistically diverse. This might be expected based on the fact that anergy must mediate silencing of B cells that bind self antigens of diverse valency and affinity. In some anergic B cells, proximal BCR signalling events appear to be intact. However, other anergic B cells are unresponsive to both BCR and TLR stimulation. Consistent among all models, however, is the inability of anergic B cells to respond to antigen by secreting immunoglobulin. Ultimately however, the goal of preventing autoimmunity is achieved. The recent discovery of An1 B cells in wild-type animals will undoubtedly open new avenues for study in this field. They provide the opportunity to study a cross-section of anergic B cells that develop in a physiological setting.

Perhaps the greatest challenge facing this field is understanding how reversibility, BCR affinity and self-antigen avidity are accommodated in silencing anergic B cells. It is easy to understand how high-avidity interactions of a BCR with self antigen, and the potent signals they induce, would lead to irreversible silencing by BCR editing or deletion. However, dealing with self-antigen avidities ranging from those that barely exceed the threshold for 
ignorance to those that approach the threshold for editing is a daunting problem, especially when one considers that the avidity of the anergy-inducing ligand may be quite different from that of a mimicking antigen presented by a pathogen that threatens to break tolerance. Although the decision to edit is analogous to a switch, anergy requires an almost infinitely variable rheostat. Although not formally proven, it is probably safe to assume that the differences observed in the features of anergic B cells from the models discussed can, in large part, be accounted for by differences in antigen avidity.

The situation becomes particularly challenging at the low-avidity end of the spectrum. At what point does anergy give way to ignorance? Although B cells in all the models described in this Review seem to be anergic at the level of attenuated in vivo immune responses, some appear to be more anergic than others with respect to signalling and early biological responses. In other models, such as the AM14 rheumatoid-factor mouse, B cells seem to be truly ignorant despite being exposed to moderate-affinity, albeit monovalent, antigen. On autoimmune-prone backgrounds, AM14 B cells make autoantibodies ${ }^{77,78}$. Understanding the mechanisms that lead to B-cell silencing in vivo, regardless of whether the self antigen is DNA or myelin, is essential in our quest to understand autoimmunity and develop new strategies for the treatment and management of these diseases.

\section{Acknowledgments}

We would like to thank S. H. Clarke, J. M. Thomas and L. J. Wysocki for their help and input.

\section{Glossary}

Receptor editing

Central tolerance

Anergy

Systemic lupus

erythematosus

MRL.Fas ${ }^{l p r / p r}$ mice

Small nuclear ribonucleoprotein
A molecular process that involves secondary rearrangements (mostly of the light chains) that replace existing immunoglobulin molecules and generate a new antigen receptor with altered specificity.

Self-tolerance that is created at the level of the central lymphoid organs. Developing T cells in the thymus and B cells in the bone marrow, that strongly recognize self antigen face deletion or marked suppression.

A state of non-responsiveness to antigen. Anergic T or B cells cannot respond to their cognate antigens under optimal conditions of stimulation.

(SLE). An autoimmune disease in which autoantibodies specific for DNA RNA or proteins associated with nucleic acids form immune complexes. These complexes damage small blood vessels, especially in the kidneys. Patients with SLE generally have abnormal B- and T-cell function.

A mouse strain that spontaneously develops glomerulonephritis and other symptoms of systemic lupus erythematosus. The $I p r$ mutation causes a defect in FAS (also known as CD95) preventing the apoptosis of activated lymphocytes the MRL strain contributes disease-associated mutations that have yet to be identified.

(snRNP). A nuclear particle that consists of a short RNA $(<300$ nucleotides) and one or more tightly bound proteins. They are involved in pre-mRNA processing and tRNA biogenesis. 


\author{
Non-obese diabetic \\ mice
}

(NOD mice). A strain of mice that normally develop idiopathic autoimmune diabetes that closely resembles type 1 diabetes in humans. The main component of susceptibility is the unique MHC haplotype $\mathrm{H}^{\mathrm{g}}{ }^{\mathrm{g}}$.

\section{References}

1. Wardemann $\mathrm{H}$, et al. Predominant autoantibody production by early human B cell precursors. Science. 2003; 301:1374-1377. [PubMed: 12920303] This paper shows that a high frequency of early immature B cells generated during human B-cell development are self-reactive.

2. Gay D, Saunders T, Camper S, Weigert M. Receptor editing: an approach by autoreactive B cells to escape tolerance. J. Exp. Med. 1993; 177:999-1008. [PubMed: 8459227]

3. Tiegs SL, Russell DM, Nemazee D. Receptor editing in self-reactive bone marrow B cells. J. Exp. Med. 1993; 177:1009-1020. [PubMed: 8459201]

4. Nemazee DA, Burki K. Clonal deletion of B lymphocytes in a transgenic mouse bearing anti-MHC class I antibody genes. Nature. 1989; 337:562-566. [PubMed: 2783762]

5. Goodnow CC, Brink R, Adams E. Breakdown of self-tolerance in anergic B lymphocytes. Nature. 1991; 352:532-536. [PubMed: 1830923]

6. Goodnow CC, et al. Altered immunoglobulin expression and functional silencing of self-reactive B lymphocytes in transgenic mice. Nature. 1988; 334:676-682. [PubMed: 3261841] This work identifies key phenotypic features of anergic cells in the classic HEL-specific B-cell model.

7. Goodnow CC, Crosbie J, Jorgensen H, Brink RA, Basten A. Induction of self-tolerance in mature peripheral B lymphocytes. Nature. 1989; 342:385-391. [PubMed: 2586609]

8. Goodnow CC, et al. Clonal silencing of self-reactive B lymphocytes in a transgenic mouse model. Cold Spring Harb. Symp. Quant. Biol. 1989; 54:907-920. [PubMed: 2701221]

9. Rui L, Vinuesa CG, Blasioli J, Goodnow CC. Resistance to CpG DNA-induced autoimmunity through tolerogenic B cell antigen receptor ERK signaling. Nature Immunol. 2003; 4:594-600. [PubMed: 12740574]

10. Rui L, Healy JI, Blasioli J, Goodnow CC. ERK signaling is a molecular switch integrating opposing inputs from B cell receptor and T cell cytokines to control TLR4-driven plasma cell differentiation. J. Immunol. 2006; 177:5337-5346. [PubMed: 17015719]

11. Shlomchik MJ, Aucoin AH, Pisetsky DS, Weigert MG. Structure and function of anti-DNA autoantibodies derived from a single autoimmune mouse. Proc. Natl Acad. Sci. USA. 1987; 84:9150-9154. [PubMed: 3480535]

12. Erikson J, et al. Expression of anti-DNA immunoglobulin transgenes in non-autoimmune mice. Nature. 1991; 349:331-334. [PubMed: 1898987]

13. Roark JH, Bui A, Nguyen KA, Mandik L, Erikson J. Persistence of functionally compromised antidouble-stranded DNA B cells in the periphery of non-autoimmune mice. Int. Immunol. 1997; 9:1615-1626. [PubMed: 9418123]

14. Nguyen KA, et al. Characterization of anti-single-stranded DNA B cells in a non-autoimmune background. J. Immunol. 1997; 159:2633-2644. [PubMed: 9300682]

15. Mandik-Nayak L. MRL-Ipr/lpr mice exhibit a defect in maintaining developmental arrest and follicular exclusion of anti-double-stranded DNA B cells. J. Exp. Med. 1999; 189:1799-1814. [PubMed: 10359584]

16. Tan EM. Antinuclear antibodies: diagnostic markers for autoimmune diseases and probes for cell biology. Adv. Immunol. 1989; 44:93-151. [PubMed: 2646863]

17. Lau CM, et al. RNA-associated autoantigens activate B cells by combined B cell antigen receptor/ Toll-like receptor 7 engagement. J. Exp. Med. 2005; 202:1171-1177. [PubMed: 16260486]

18. Bloom DD, Davignon JL, Cohen PL, Eisenberg RA, Clarke SH. Overlap of the anti-Sm and antiDNA responses of MRL/Mp-Ipr/lpr mice. J. Immunol. 1993; 150:1579-1590. [PubMed: 8432994] 
19. Qian Y, et al. Autoreactive MZ and B-1 B-cell activation by Fas ${ }^{l p r}$ is coincident with an increased frequency of apoptotic lymphocytes and a defect in macrophage clearance. Blood. 2006; 108:974982. [PubMed: 16861350]

20. Qian Y, Wang H, Clarke SH. Impaired clearance of apoptotic cells induces the activation of autoreactive anti-Sm marginal zone and B-1 B cells. J. Immunol. 2004; 172:625-635. [PubMed: 14688375]

21. Culton DA, et al. Early preplasma cells define a tolerance checkpoint for autoreactive B cells. J. Immunol. 2006; 176:790-802. [PubMed: 16393962]

22. Santulli-Marotto S, Retter MW, Gee R, Mamula MJ, Clarke SH. Autoreactive B cell regulation: peripheral induction of developmental arrest by lupus-associated autoantigens. Immunity. 1998; 8:209-219. [PubMed: 9492002]

23. Retter MW, Eisenberg RA, Cohen PL, Clarke SH. Sm and DNA binding by dual reactive B cells requires distinct $\mathrm{V}_{\mathrm{H}}, \mathrm{V}_{\mathrm{K}}$, and $\mathrm{V}_{\mathrm{H}}$ CDR3 structures. J. Immunol. 1995; 155:2248-2257. [PubMed: 7636271]

24. Borrero M, Clarke SH. Low-affinity anti-Smith antigen B cells are regulated by anergy as opposed to developmental arrest or differentiation to B-1. J. Immunol. 2002; 168:13-21. [PubMed: 11751941]

25. Ewulonu UK, Nell LJ, Thomas JW. $\mathrm{V}_{\mathrm{H}}, \mathrm{V}_{\mathrm{L}}$ gene usage by murine IgG antibodies that bind autologous insulin. J. Immunol. 1990; 144:3091-3098. [PubMed: 2109009]

26. Rojas M, Hulbert C, Thomas JW. Anergy and not clonal ignorance determines the fate of B cells that recognize a physiological autoantigen. J. Immunol. 2001; 166:3194-3200. [PubMed: 11207272]

27. Acevedo-Suarez CA, Hulbert C, Woodward EJ, Thomas JW. Uncoupling of anergy from developmental arrest in anti-insulin B cells supports the development of autoimmune diabetes. J. Immunol. 2005; 174:827-833. [PubMed: 15634904]

28. Benschop RJ, et al. Activation and anergy in bone marrow B cells of a novel immunoglobulin transgenic mouse that is both hapten specific and autoreactive. Immunity. 2001; 14:33-43. [PubMed: 11163228]

29. Merrell KT, et al. Identification of anergic B cells within a wild-type repertoire. Immunity. 2006; 25:953-962. [PubMed: 17174121]

30. Gauld SB, Benschop RJ, Merrell KT, Cambier JC. Maintenance of B cell anergy requires constant antigen receptor occupancy and signaling. Nature Immunol. 2005; 6:1160-1167. [PubMed: 16200069] This paper suggests that anergy is a rapidly reversible phenotype that is dependent on constant self-antigen binding to the antigen receptor.

31. Teague BN, et al. Cutting Edge: Transitional t 3 B cells do not give rise to mature B cells, have undergone selection, and are reduced in murine lupus. J. Immunol. 2007; 178:7511-7515. [PubMed: 17548583]

32. Mandik-Nayak L, Bui A, Noorchashm H, Eaton A, Erikson J. Regulation of anti-double-stranded DNA B cells in nonautoimmune mice: localization to the T-B interface of the splenic follicle. J. Exp. Med. 1997; 186:1257-1267. [PubMed: 9334365]

33. Noorchashm H, et al. Characterization of anergic anti-DNA B cells: B cell anergy is a T cellindependent and potentially reversible process. Int. Immunol. 1999; 11:765-776. [PubMed: 10330282]

34. Fulcher DA, Basten A. Reduced life span of anergic self-reactive B cells in a double-transgenic model. J. Exp. Med. 1994; 179:125-134. [PubMed: 8270860] This paper is one of several key studies that identify the short half-life of self-reactive B cells.

35. Tough DF, Sprent J. Lifespan of lymphocytes. Immunol. Res. 1995; 14:1-12. [PubMed: 7561338]

36. Cyster JG, Hartley SB, Goodnow CC. Competition for follicular niches excludes self-reactive cells from the recirculating B-cell repertoire. Nature. 1994; 371:389-395. [PubMed: 7522305] This work shows that competition of anergic B cells within a normal B-cell repertoire contributes to their short lifespan.

37. Cyster JG, Goodnow CC. Antigen-induced exclusion from follicles and anergy are separate and complementary processes that influence peripheral B cell fate. Immunity. 1995; 3:691-701. 
[PubMed: 8777715] This paper highlights the exclusion of self-reactive B cells from follicular areas and shows their localization to the T-cell-B-cell interface.

38. Mackay F, Schneider P, Rennert P, Browning J. BAFF AND APRIL: a tutorial on B cell survival. Annu. Rev. Immunol. 2003; 21:231-264. [PubMed: 12427767]

39. Lesley R, et al. Reduced competitiveness of autoantigen-engaged B cells due to increased dependence on BAFF. Immunity. 2004; 20:441-453. [PubMed: 15084273] This paper shows the reduced capacity of self-reactive B cells to compete for the B-cell survival signal BAFF, thereby contributing to their short lifespan.

40. Oliver PM, Vass T, Kappler J, Marrack P. Loss of the proapoptotic protein, Bim, breaks B cell anergy. J. Exp. Med. 2006; 203:731-741. [PubMed: 16520387]

41. Mandik-Nayak L, et al. Functional consequences of the developmental arrest and follicular exclusion of anti-double-stranded DNA B cells. J. Immunol. 2000; 164:1161-1168. [PubMed: 10640726]

42. Weintraub JP, et al. Immunological and pathological consequences of mutations in both Fas and Fas ligand. Cell. Immunol. 1998; 186:8-17. [PubMed: 9637760]

43. Rathmell JC, et al. CD95 (Fas)-dependent elimination of self-reactive B cells upon interaction with $\mathrm{CD}^{+}{ }^{+}$T cells. Nature. 1995; 376:181-184. [PubMed: 7603571]

44. Rathmell JC, Fournier S, Weintraub BC, Allison JP, Goodnow CC. Repression of B7.2 on selfreactive $\mathrm{B}$ cells is essential to prevent proliferation and allow Fas-mediated deletion by $\mathrm{CD}^{+} \mathrm{T}$ cells. J. Exp. Med. 1998; 188:651-659. [PubMed: 9705947]

45. Feuerstein N, Chen F, Madaio M, Maldonado M, Eisenberg RA. Induction of autoimmunity in a transgenic model of $\mathrm{B}$ cell receptor peripheral tolerance: changes in coreceptors and B cell receptor-induced tyrosine-phosphoproteins. J. Immunol. 1999; 163:5287-5297. [PubMed: 10553051]

46. Sekiguchi DR, et al. Chronic graft-versus-host in Ig knockin transgenic mice abrogates B cell tolerance in anti-double-stranded DNA B cells. J. Immunol. 2002; 168:4142-4153. [PubMed: 11937575]

47. Seo SJ, et al. The impact of $\mathrm{T}$ helper and $\mathrm{T}$ regulatory cells on the regulation of anti-doublestranded DNA B cells. Immunity. 2002; 16:535-546. [PubMed: 11970877]

48. Cooke MP, et al. Immunoglobulin signal transduction guides the specificity of B cell-T cell interactions and is blocked in tolerant self-reactive B cells. J. Exp. Med. 1994; 179:425-438. [PubMed: 8294858]

49. Foote LC, Marshak-Rothstein A, Rothstein TL. Tolerant B lymphocytes acquire resistance to Fasmediated apoptosis after treatment with interleukin 4 but not after treatment with specific antigen unless a surface immunoglobulin threshold is exceeded. J. Exp. Med. 1998; 187:847-853. [PubMed: 9500787]

50. Cook MC, Basten A, Fazekas de St Groth B. Rescue of self-reactive B cells by provision of T cell help in vivo . Eur. J. Immunol. 1998; 28:2549-2558. [PubMed: 9710232]

51. Reif K, et al. Balanced responsiveness to chemoattractants from adjacent zones determines B-cell position. Nature. 2002; 416:94-99. [PubMed: 11882900]

52. Pisitkun $P$, et al. Autoreactive B cell responses to RNA-related antigens due to TLR7 gene duplication. Science. 2006; 312:1669-1672. [PubMed: 16709748]

53. Kilmon MA, Rutan JA, Clarke SH, Vilen BJ. Low-affinity, Smith antigen-specific B cells are tolerized by dendritic cells and macrophages. J. Immunol. 2005; 175:37-41. [PubMed: 15972629]

54. Gilbert MR, et al. Dendritic cells from lupus-prone mice are defective in repressing immunoglobulin secretion. J. Immunol. 2007; 178:4803-4810. [PubMed: 17404261]

55. Kilmon MA, et al. Macrophages prevent the differentiation of autoreactive B cells by secreting CD40 ligand and IL-6. Blood. in the press.

56. Lenschow DJ, et al. Differential up-regulation of the B7-1 and B7-2 costimulatory molecules after Ig receptor engagement by antigen. J. Immunol. 1994; 153:1990-1997. [PubMed: 7519638]

57. Vilen BJ, Famiglietti SJ, Carbone AM, Kay BK, Cambier JC. B cell antigen receptor desensitization: disruption of receptor coupling to tyrosine kinase activation. J. Immunol. 1997; 159:231-243. [PubMed: 9200459] 
58. Vilen BJ, Burke KM, Sleater M, Cambier JC. Transmodulation of BCR signaling by transductionincompetent antigen receptors: implications for impaired signaling in anergic B cells. J. Immunol. 2002; 168:4344-4351. [PubMed: 11970976]

59. Weintraub BC, et al. Entry of B cell receptor into signaling domains is inhibited in tolerant B cells. J. Exp. Med. 2000; 191:1443-1448. [PubMed: 10770810] This paper highlights defective B-cell signalling by anergic B cells.

60. Healy JI, et al. Different nuclear signals are activated by the B cell receptor during positive versus negative signaling. Immunity. 1997; 6:419-428. [PubMed: 9133421] This work highlights key signalling phenotypes of self-reactive B cells.

61. Acevedo-Suarez CA, Kilkenny DM, Reich MB, Thomas JW. Impaired intracellular calcium mobilization and NFATc1 availability in tolerant anti-insulin B cells. J. Immunol. 2006; 177:2234-2241. [PubMed: 16887983]

62. Radic M, Marion T, Monestier M. Nucleosomes are exposed at the cell surface in apoptosis. J. Immunol. 2004; 172:6692-6700. [PubMed: 15153485]

63. Leadbetter EA, et al. Chromatin-IgG complexes activate B cells by dual engagement of IgM and Toll-like receptors. Nature. 2002; 416:603-607. [PubMed: 11948342]

64. Ho WY, Cooke MP, Goodnow CC, Davis MM. Resting and anergic B cells are defective in CD28dependent costimulation of naive CD4 ${ }^{+}$T cells. J. Exp. Med. 1994; 179:1539-1549. [PubMed: 7909325]

65. Eris JM, et al. Anergic self-reactive B cells present self antigen and respond normally to CD40dependent T-cell signals but are defective in antigen-receptor-mediated functions. Proc. Natl Acad. Sci. USA. 1994; 91:4392-4396. [PubMed: 7514304]

66. Rathmell JC, Townsend SE, Xu JC, Flavell RA, Goodnow CC. Expansion or elimination of B cells in vivo: dual roles for CD40- and Fas (CD95)-ligands modulated by the B cell antigen receptor. Cell. 1996; 87:319-329. [PubMed: 8861915]

67. Smith KG, Tarlinton DM, Doody GM, Hibbs ML, Fearon DT. Inhibition of the B cell by CD22: a requirement for Lyn. J. Exp. Med. 1998; 187:807-811. [PubMed: 9480991]

68. O'Keefe TL, Williams GT, Batista FD, Neuberger MS. Deficiency in CD22, a B cell-specific inhibitory receptor, is sufficient to predispose to development of high affinity autoantibodies. J. Exp. Med. 1999; 189:1307-1313. [PubMed: 10209047]

69. Hibbs ML, et al. Sustained activation of Lyn tyrosine kinase in vivo leads to autoimmunity. J. Exp. Med. 2002; 196:1593-1604. [PubMed: 12486102]

70. Pao LI, Famiglietti SJ, Cambier JC. Asymmetrical phosphorylation and function of immunoreceptor tyrosine-based activation motif tyrosines in B cell antigen receptor signal transduction. J. Immunol. 1998; 160:3305-3314. [PubMed: 9531288]

71. Miyamoto A, et al. Increased proliferation of B cells and auto-immunity in mice lacking protein kinase C8. Nature. 2002; 416:865-859. [PubMed: 11976687]

72. Mecklenbrauker I, Saijo K, Zheng NY, Leitges M, Tarakhovsky A. Protein kinase C $\delta$ controls selfantigen-induced B-cell tolerance. Nature. 2002; 416:860-865. [PubMed: 11976686]

73. Mecklenbrauker I, Kalled SL, Leitges M, Mackay F, Tarakhovsky A. Regulation of B-cell survival by BAFF-dependent PKC $\delta$-mediated nuclear signalling. Nature. 2004; 431:456-461. [PubMed: 15361883]

74. Mackay F, et al. Mice transgenic for BAFF develop lymphocytic disorders along with autoimmune manifestations. J. Exp. Med. 1999; 190:1697-1710. [PubMed: 10587360]

75. Brauweiler A, Merrell K, Gauld SB, Cambier JC. Cutting Edge: Acute and chronic exposure of immature B cells to antigen leads to impaired homing and SHIP1-dependent reduction in stromal cell-derived factor-1 responsiveness. J. Immunol. 2007; 178:3353-3357. [PubMed: 17339427]

76. Thien M, et al. Excess BAFF rescues self-reactive B cells from peripheral deletion and allows them to enter forbidden follicular and marginal zone niches. Immunity. 2004; 20:785-798. [PubMed: 15189742]

77. Shlomchik MJ, Euler CW, Christensen SC, William J. Activation of rheumatoid factor (RF) B cells and somatic hypermutation outside of germinal centers in autoimmune-prone MRL/ lpr mice. Ann. N.Y. Acad. Sci. 2003; 987:38-50. [PubMed: 12727622] 
78. Wang H, Shlomchik MJ. Autoantigen-specific B cell activation in Fas-deficient rheumatoid factor immunoglobulin transgenic mice. J. Exp. Med. 1999; 190:639-649. [PubMed: 10477549]

79. Pugh-Bernard AE, et al. Regulation of inherently autoreactive $V_{H^{4}}-34$ B cells in the maintenance of human B cell tolerance. J. Clin. Invest. 2001; 108:1061-1070. [PubMed: 11581307]

80. Stevenson FK, Smith GJ, North J, Hamblin TJ, Glennie MJ. Identification of normal B-cell counterparts of neoplastic cells which secrete cold agglutinins of anti-I and anti-i specificity. Br. J. Haematol. 1989; 72:9-15. [PubMed: 2472169]

81. Isenberg DA, et al. Correlation of 9G4 idiotope with disease activity in patients with systemic lupus erythematosus. Ann. Rheum. Dis. 1998; 57:566-570. [PubMed: 9849317]

82. van Vollenhoven RF, et al. $\mathrm{V}_{\mathrm{H}^{4}}-34$ encoded antibodies in systemic lupus erythematosus: a specific diagnostic marker that correlates with clinical disease characteristics. J. Rheumatol. 1999; 26:1727-1733. [PubMed: 10451069]

83. Allman D, et al. Resolution of three nonproliferative immature splenic B cell subsets reveals multiple selection points during peripheral B cell maturation. J. Immunol. 2001; 167:6834-6840. [PubMed: 11739500] 


\section{Box 1 | Anergy in humans}

Although humans ${ }^{1}$ and mice both produce self-reactive B cells at high frequency in the bone marrow, only in mice has a self-reactive anergic B-cell population been identified in the periphery. Therefore, it has not been possible to study the role that anergy has in preventing human autoimmune disease, nor to compare the signalling and phenotypic characteristics of human versus mouse anergic B cells. Studies have found that human B cells using the immunoglobulin heavy chain gene $\mathrm{V}_{\mathrm{H}} 4-34$ are inheritably self-reactive, independent of immunoglobulin light-chain usage ${ }^{79}$. Indeed, serum levels of $\mathrm{V}_{\mathrm{H}}$ 4-34containing antibodies account for approximately $0.5 \%$ of total immunoglobulin in healthy humans ${ }^{80}$. In patients with systemic lupus erythematosus, the levels of these antibodies are increased and correlate with disease ${ }^{81,82}$. However, it is unclear whether these B cells, which are good candidates for a human anergic B-cell population, also express novel cell-surface markers that can be used to isolate these cells from human tissue. Such information, as we now have for a population in mice, would allow us to monitor the entrance and departure of autoreactive clonotypes from the anergic compartment and thus begin to understand the forces that drive autoimmunity in humans. 


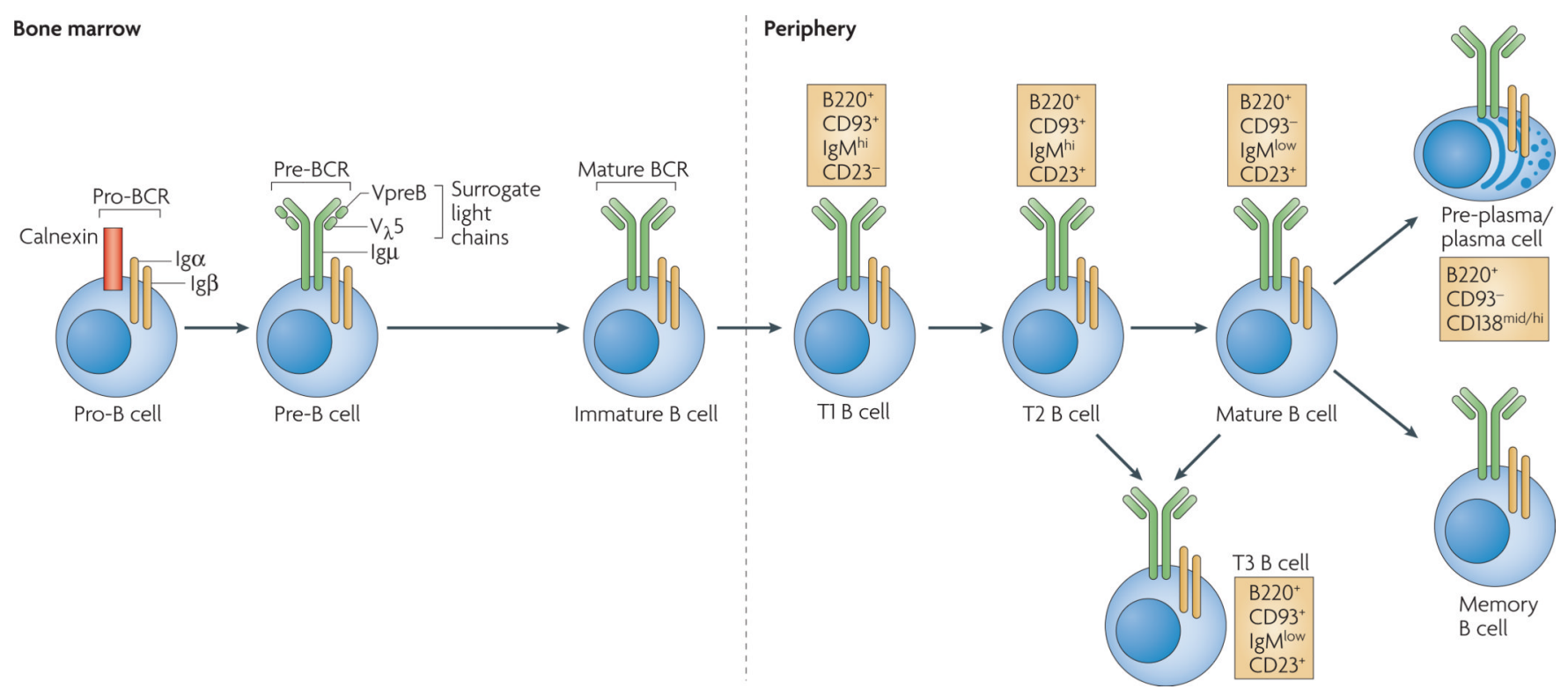

Figure 1. Stages of B-cell development

B-cell development occurs in both the bone marrow and peripheral lymphoid tissues such as the spleen. In the bone marrow, development progresses through the pro-B-cell, pre-B-cell and immature-B-cell stages. During this differentiation, rearrangements at the immunoglobulin locus result in the generation and surface expression of the pre-B-cell receptor (pre-BCR, which is comprised of an Ig $\mu$ heavy chain and surrogate light chains (VpreB or $\left.\mathrm{V}_{\lambda} 5\right)$ ) and finally a mature BCR (comprised of rearranged heavy- and light-chain genes) that is capable of binding antigen. At this immature stage of development, B cells undergo a selection process to prevent any further development of self-reactive cells. Both receptor editing and clonal deletion have a role at this stage. Cells successfully completing this checkpoint leave the bone marrow as transitional B cells, eventually maturing into mature follicular B cells (or marginal-zone B cells). Following an immune response, antigen-specific B cells develop into either plasma (antibody-secreting) cells or memory B cells. Transitional 3 (T3) B cells, once thought to be part of the linear development from immature to mature B cells, are now thought to represent primarily self-reactive anergic B cells (also known as An1 B cells). 
a Acute antigen signalling

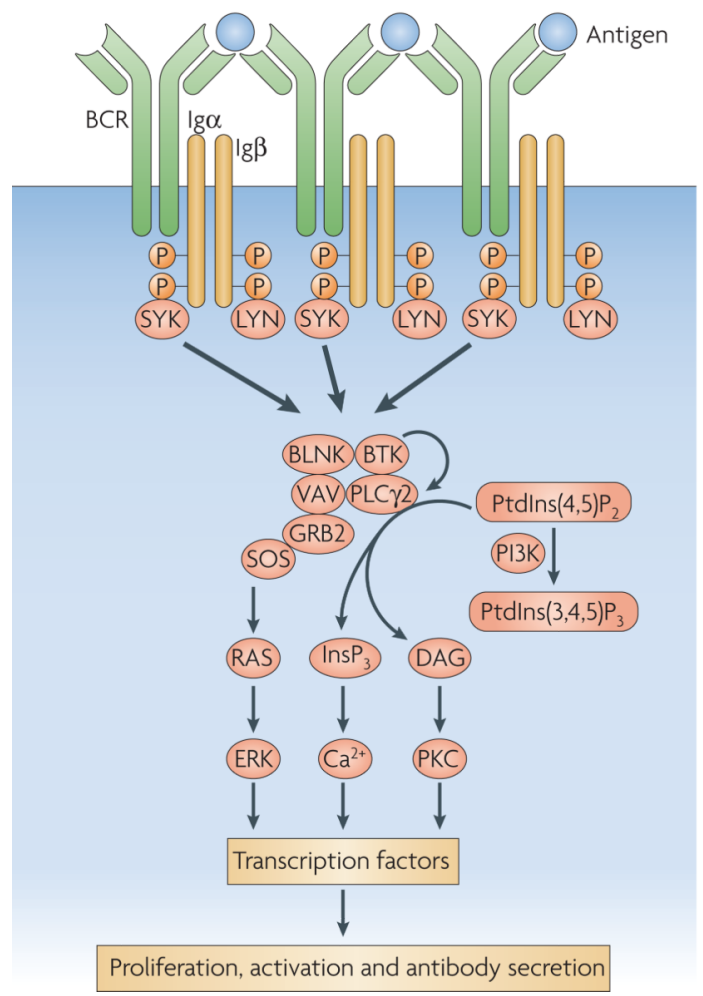

b Chronic antigen signalling

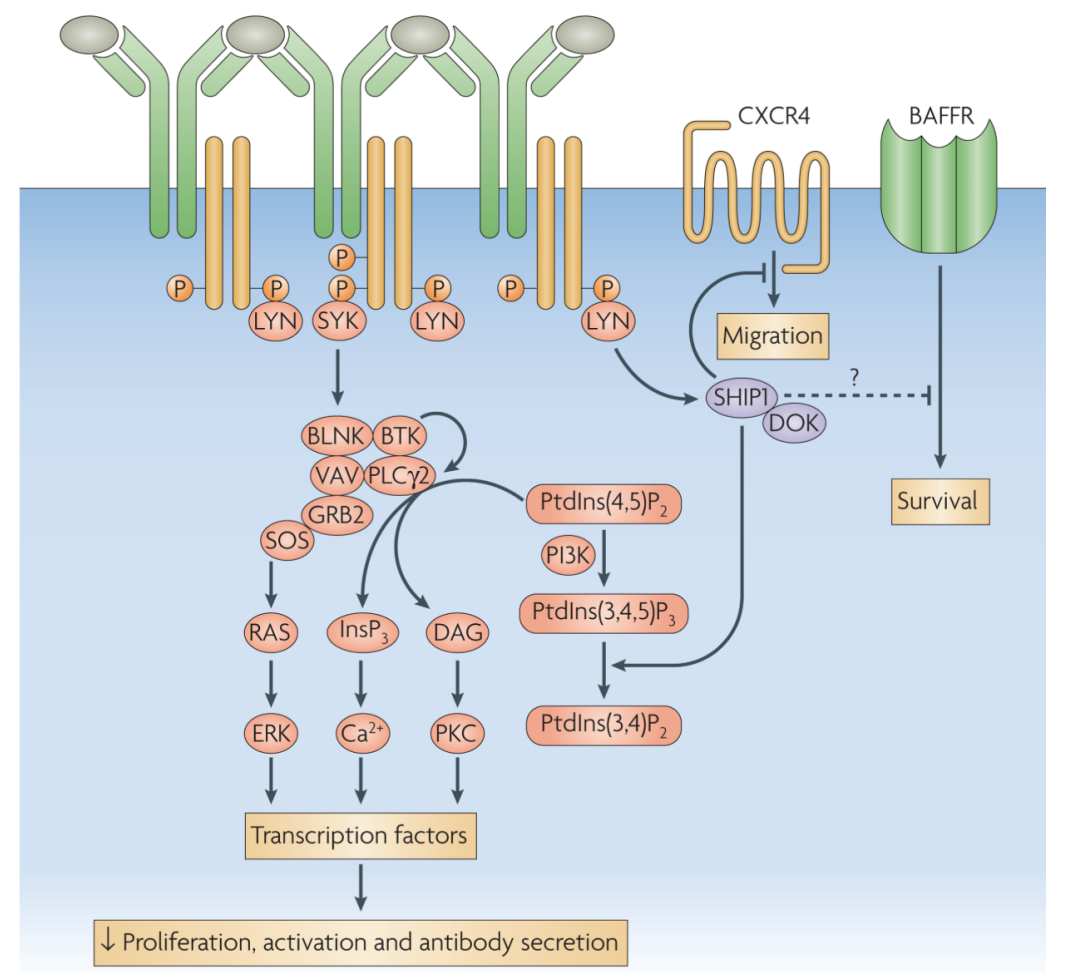

Figure 2. B-cell signalling in response to acute or chronic antigen stimulation

a | The normal B-cell receptor (BCR) response to acute antigen stimulation involves the phosphorylation of two tyrosine residues in the ITAMs (immunoreceptor tyrosine-based activation motifs) of Iga and Ig $\beta$ by LYN or other SRC-family kinases. This results in the recruitment and activation of SYK (spleen tyrosine kinase), which in turn phosphorylates key downstream substrates such as BLNK (B-cell linker) and BTK (Bruton's tyrosine kinase), resulting in productive BCR signalling, activation and productive interactions with helper T cells. b In anergic B cells, chronic binding of self antigen is thought to favour monophosphorylation of ITAM tyrosines. This limits the recruitment and activation of SYK, yet allows efficient LYN activity, which enhances the phosphorylation and activation of an inhibitory complex containing SHIP1 (SRC-homology-2-domain-containing inositol-5phosphatase 1) and DOK (docking protein). These proteins act to dampen any productive BCR-mediated signalling in a manner that is analogous to Fc $\gamma$ RIIb (an inhibitory Fc receptor for $\mathrm{IgG}$ that is expressed by $\mathrm{B}$ cells). This inhibitory complex may also act in trans to inhibit signalling by other receptors, including CXC-chemokine receptor 4 (CXCR4) and possibly the receptor for B-cell-activating factor (BAFFR). DAG, diacylglycerol; ERK, extracellular-signal-regulated kinase; GRB2, growth-factor-receptor-bound protein 2; $\operatorname{InsP}_{3}$, inositol-1,4,5-trisphosphate; PI3K, phosphoinositide 3-kinase; PKC, protein kinase C; PLC $\gamma$, phospholipase $\mathrm{C} \gamma$; PtdIns $(3,4,5) \mathrm{P}_{3}$, phosphatidylinositol-3,4,5-trisphosphate; PtdIns $(4,5) \mathrm{P}_{2}$, phosphatidylinositol-4,5-bisphosphate; SOS, son-of-sevenless homologue. 


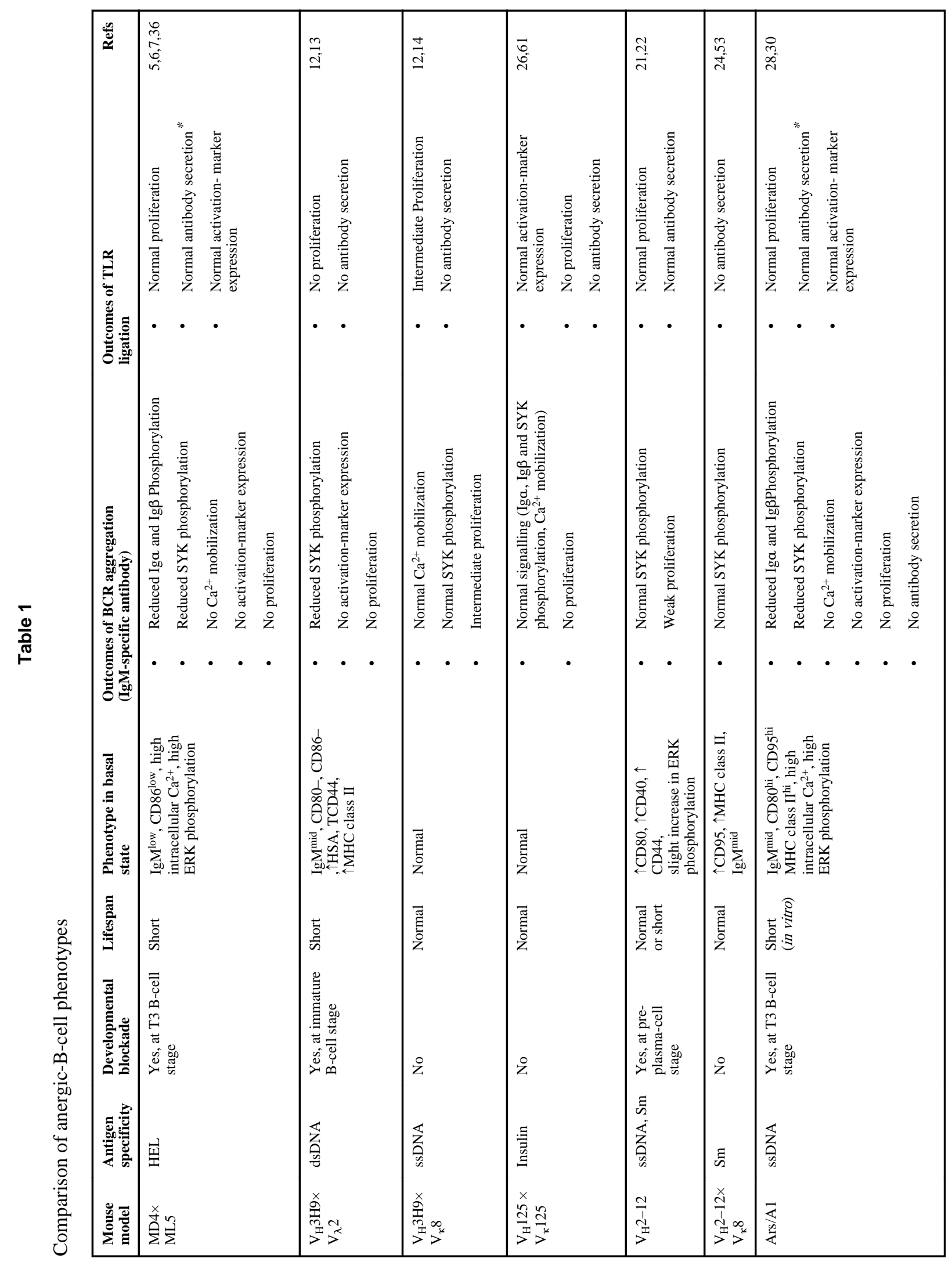

Nat Rev Immunol. Author manuscript; available in PMC 2013 July 17. 


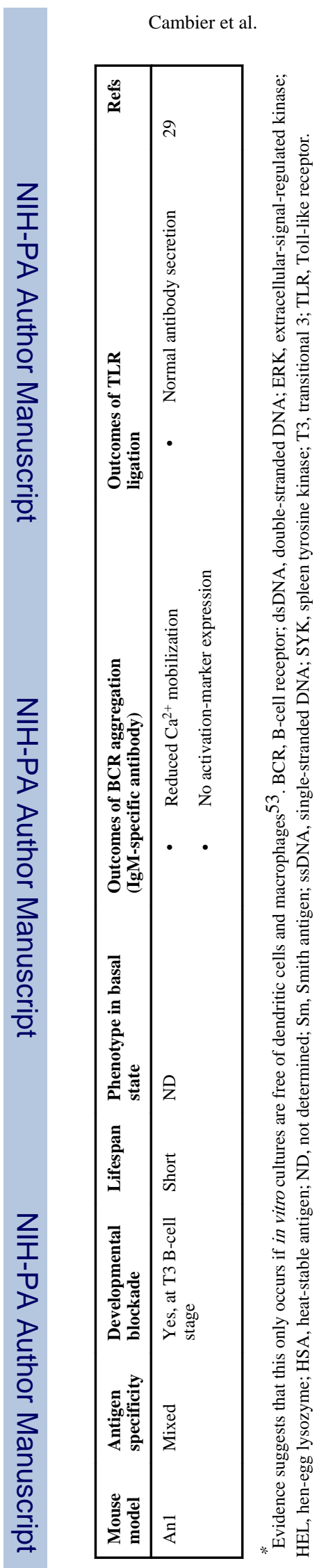

Nat Rev Immunol. Author manuscript; available in PMC 2013 July 17. 